Article

\title{
Field Emission and Emission-Stimulated Desorption of ZnO Nanomaterials
}

\author{
Nannan $\mathrm{Li}^{1,2, *}$, Xiaozhao $\mathrm{Li}^{1}$ and Baoqing Zeng ${ }^{2}$ \\ 1 Micro/Nano Fabrication Laboratory, Microsystem \& Terahertz Research Center, CAEP, Chengdu 610200, \\ China; lixiaozhao@mtrc.ac.cn \\ 2 National Key Laboratory of Science and Technology on Vacuum Electronics, School of Physical Electronics, \\ University of Electronic Science and Technology of China, Chengdu 610054, China; bqzeng@uestc.edu.cn \\ * Correspondence: linannan@mtrc.ac.cn; Tel.: +86-028-65726019
}

Received: 13 January 2018; Accepted: 27 February 2018; Published: 6 March 2018

Featured Application: Zinc oxide $(\mathrm{ZnO})$ nanomaterials have attracted considerable scientific interest due to their promising potential in extensive applications, such as nanolasers, light-emitting diodes, photovoltaic devices, and gas sensors. In this paper, the research focused mainly on geometric effects, emission stability, and ambient insensitivity of $\mathrm{ZnO}$ nanomaterials. We report the field emission and emission-stimulated desorption of $\mathrm{ZnO}$ nanomaterials, which makes it possible to use them as field emitter cathodes in harsh environments with fluctuating pressure.

\begin{abstract}
Compared with other field-emission nanomaterials, $1 \mathrm{D} \mathrm{ZnO}$ nanomaterials have some unique properties—such as high melting point, high thermal and chemical stability, and ambient insensitivity-which means they have promising potential applications as field emitters in harsh environments. This work proposed a water-assisted physical vapor deposition method to prepare various $\mathrm{ZnO}$ nanostructures simultaneously on a silicon substrate with one experimental run. Field emission characteristics of the as-grown $\mathrm{ZnO}$ nanomaterials were measured and analyzed. Emission-stimulated desorption was proposed and investigated. The gas released under the emission-stimulated desorption effect was measured in the way of monitoring the variation of the pressure. The results show that the slight variation of the pressure has almost no effects on the field-emissions, and field emission properties can be improved with the gases released from the surface of $\mathrm{ZnO}$ under the emission-stimulated-desorption effect. Finally, a low turn-on voltage in the range of $0.5-0.9 \mathrm{~V} / \mu \mathrm{m}$ was achieved and a stable emission current was obtained. The ambient insensitivity of $\mathrm{ZnO}$ nanomaterials make them possible to be used as field emission cathodes in harsh environments with fluctuating pressure.
\end{abstract}

Keywords: $\mathrm{ZnO}$ nanomaterials; field emission; emission-stimulated desorption

\section{Introduction}

Zinc oxide $(\mathrm{ZnO})$ nanomaterials are attractive semiconductor materials for nanodevices due to their excellent properties-such as wide direct band gap, large exciting binding energy, piezoelectric, biocompatible, and high chemical stability — which means they have potential applications in advanced optoelectronic devices including nanolaser, light-emitting diodes, photovoltaic devices, and gas sensors. With high aspect ratio and good thermal and chemical stability, 1D ZnO nanomaterials are genuine candidates of field emitters. High-quality field emitters are desirable for applications in a wide range of field-emission-based devices such as high brightness electron source, panel displays, microwave amplifiers, and X-ray sources. In recent years, many efforts have been invested in the studies of field emission from 0D nanoparticles [1,2], 1D nanotube [3,4] or nanowires [5], and 2D graphene [6]. 
1D nanomaterials have garnered the most attention due to their geometric effects. Among 1D nanomaterials, carbon nanotubes (CNTs) have been studied extensively for field emission due to their high aspect ratio. However, besides the geometric effects, there are also several key factors such as thermal stability and ambient insensitivity which have important effects on field emission. $\mathrm{ZnO}$, as an oxide, exhibits a high melting point and stability in harsh environments. 1D ZnO-based nanostructures—like nanowires [7,8], nanoneedles [9,10], nanorods [11], and nanocombs [12]—have been demonstrated to be appropriate as field emitters. $\mathrm{ZnO}$ nanomaterials can be synthesized by using the solution-phase method [13] or vapor-phase method [14,15]. Among vapor-phase methods, physical vapor deposition [15] is a low-temperature approach which is widely used. In this work, a water-assisted physical vapor deposition method was proposed and used to prepare various $\mathrm{ZnO}$ nanostructures on a silicon substrate with one experimental run. To examine the stability of the $\mathrm{ZnO}$ nanomaterials, field emission characteristics were measured two years later. During the field emission process, emission-stimulated desorption would be accompanied. Emission-stimulated desorption is an important process which has effects on the field emission properties. However, there are few reports on the emission-stimulated desorption process, which stimulates our work on the field emission and emission-stimulated desorption of $\mathrm{ZnO}$ nanomaterials. The gas released was measured in the way of monitoring the variation of pressure in vacuum chamber. Field emission was enhanced with the gases desorption from the surface of $\mathrm{ZnO}$ nanomaterials. Finally, a low turn-on voltage in the range of $0.5 \sim 0.9 \mathrm{~V} / \mu \mathrm{m}$ and a stable emission current were obtained.

\section{Materials and Methods}

$\mathrm{ZnO}$ nanostructures were grown on a (100)-oriented $n$-type silicon substrate (dimensions: $10 \times 20 \mathrm{~mm}$ ) using a water assisted zinc source method. The fabricating process was carried out by using the system with a horizontal quartz tube placed in the furnace (see Figure 1).

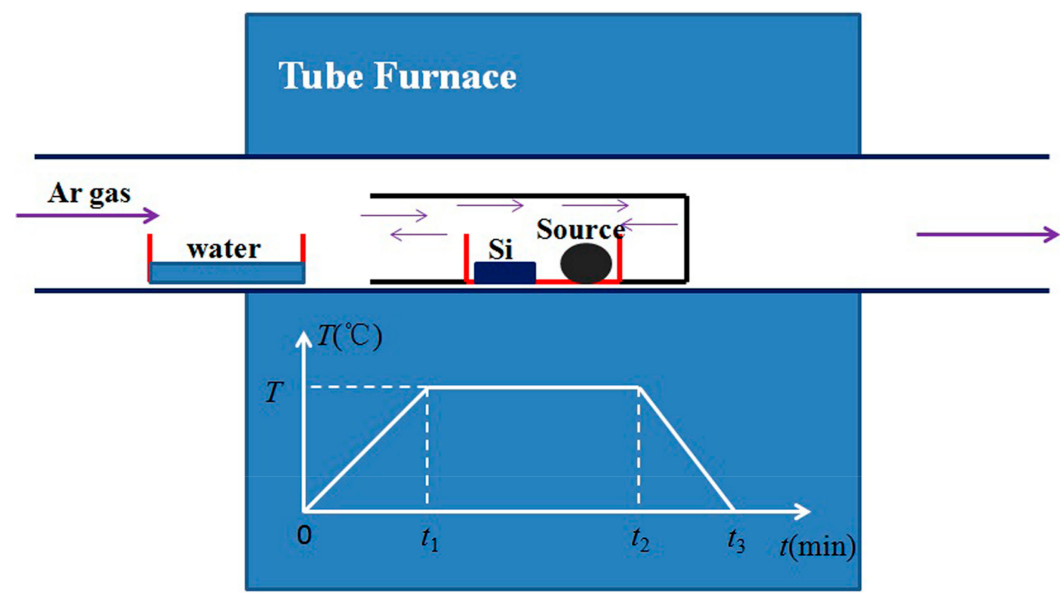

Figure 1. Schematic illustration of $\mathrm{ZnO}$ nanomaterial fabricating process using the system with a horizontal quartz tube placed in the furnace.

Firstly, $1 \mathrm{~g}$ Zn powders (purity 99.99\%) used as the source was grinded and placed at the end of a ceramic boat. In the same boat, a piece of silicon substrate was placed at the other end for growing $\mathrm{ZnO}$ nanomaterials. Before loading the substrate into the ceramic boat, the silicon was firstly etched using hydrofluoric acid for about $10 \mathrm{~min}$, then ultrasonically cleaned successively in acetone, ethanol, and deionized water for $15 \mathrm{~min}$ for each step, and finally was deposited with a $10 \mathrm{~nm} \mathrm{Au}$ film on the surface by sputtering. The boat was then placed in a quartz vial inside a horizontal-tube furnace (see Figure 1). Another boat with $4 \mathrm{~mL}$ water was placed at the gas direction of the port of the horizontal-tube furnace. The system was vacuumed by a mechanical pump to KPa level, and then the furnace was heated to reaction temperature $730{ }^{\circ} \mathrm{C}$ at a rate of $20^{\circ} \mathrm{C} / \mathrm{min}$, and kept for $40 \mathrm{~min}$ 
under argon (Ar) flow of $50 \mathrm{sccm}$. The Ar flow was used as gas carrier, which carried water vapor into the quartz vial inside the horizontal-tube furnace. The water vapor can provide oxygen for the oxidation of $\mathrm{Zn}$. The $\mathrm{Zn}$ powder would gradually vaporize to fill the quartz vial and then diffuse to the substrate when the temperature went above the melting point of zinc metal $\left(420^{\circ} \mathrm{C}\right)$. The $\mathrm{Au}$ particles on the substrate formed colloidal droplets, which became super-saturated with zinc vapor. $\mathrm{ZnO}$ nanostructures were synthesized on the silicon substrate via a vapor-liquid-solid (VLS) growth mechanism. The colloidal Au nanoparticles on the Si surface served as catalysts in the VLS synthesis mechanism. It has been reported that native defects, such as zinc interstitials and oxygen vacancies, may lead to the n-type semiconducting behavior of $\mathrm{ZnO}$, and the defects serve as donors with a binding energy of 30-60 meV $[16,17]$.

After the furnace cooled down, a bluish-white layer was observed on the substrate surface. Scanning electron microscopy (SEM) was employed to investigate the morphology of the as-grown $\mathrm{ZnO}$ nanomaterials. Energy dispersive spectroscopy (EDS) was used to analyze the composition of $\mathrm{ZnO}$ nanomaterials.

\section{Results}

Various $\mathrm{ZnO}$ nanostructures were obtained on silicon substrates by using water assisted zinc source method. The representative SEM images (Figure 2) taken from different area of the substrate have revealed the different morphologies of $\mathrm{ZnO}$ nanostructure arrays. The $\mathrm{ZnO}$ nanowires (ZNWs) (see Figure 2a) with around $12.7 \mu \mathrm{m}$ long were synthesized under a more traditional VSL process. The ZNWs were distributed in very high coverage density. Hexagonal prismatic nanorods of $\mathrm{ZnO}$ (see Figure $2 b$ ) have orientation almost perpendicular to the substrate, and are aligned in higher coverage density. The $\mathrm{ZnO}$ nanoneedles (see Figure 2c) with around $5.6 \mu \mathrm{m}$ length and diameter of $102 \mathrm{~nm}$ sharp head were also synthesized due to a relatively high oxygen concentration in the local area. The $\mathrm{ZnO}$ crystals would grow into thicker needle-like structures when the concentration of oxygen is higher. $\mathrm{ZnO}$ comblike structures (see Figure 2d) were also created due to the polar surface growth [18]. The variation of crystal growth should be attributed to the spatial change of $\mathrm{Zn}$ and $\mathrm{O}_{2}$ concentration distribution inside the quartz vial. It can be found from the direction of gas flow (see Figure 1) that the gas pressure is different at the different location in the small quartz vial. The vapor inside the quartz vial would be brought out finally. Therefore, the closer the substrate gets to the export of the quartz vial, the more products of $\mathrm{ZnO}$ nanostructures will be obtained.

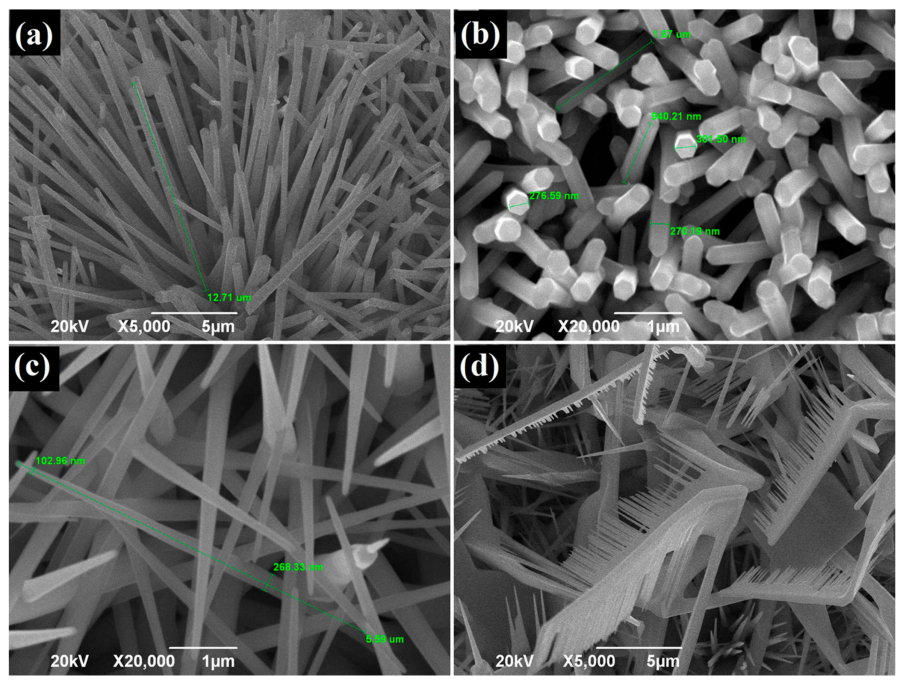

Figure 2. Scanning electron microscopy (SEM) images of $\mathrm{ZnO}$ nanomaterials grown on silicon substrate. (a) $\mathrm{ZnO}$ nanowires (ZNWs), (b) $\mathrm{ZnO}$ nanorods with hexagonal crystal structure, (c) $\mathrm{ZnO}$ nanoneedles, (d) $\mathrm{ZnO}$ nanocombs. 
The vapor concentration of zinc and oxygen plays an important role in the synthesis of $\mathrm{ZnO}$ nanomaterials which is determined by the relative rate of surface reaction with respect to the mass transfer. At the part of the substrate closed to zinc source, where oxygen had the lowest but zinc vapor had the highest concentration, the surface-reaction-limited situation dominated the reaction. In other words, the mass transfer rate was higher, which is beneficial for the growth of nanostructure with high aspect ratio. At the area of the substrate closed to the port of the quartz vial, a smaller concentration difference between zinc vapor and oxygen leaded to a higher nucleation rate which made nanowires grow into branch. The mass-transfer-controlled process dominated the reaction. Conclusively, to obtain certain kind of $\mathrm{ZnO}$ nanostructure, it is necessary to balance a proper mass-transfer process and surface-reaction effects. The EDS spectrum of the ZNWs is depicted in Figure 3. Only the peaks associated with $\mathrm{Zn}$ and $\mathrm{O}$ atoms are seen in the EDS spectrum demonstrated qualitatively that the nanomaterials are indeed $\mathrm{ZnO}$.

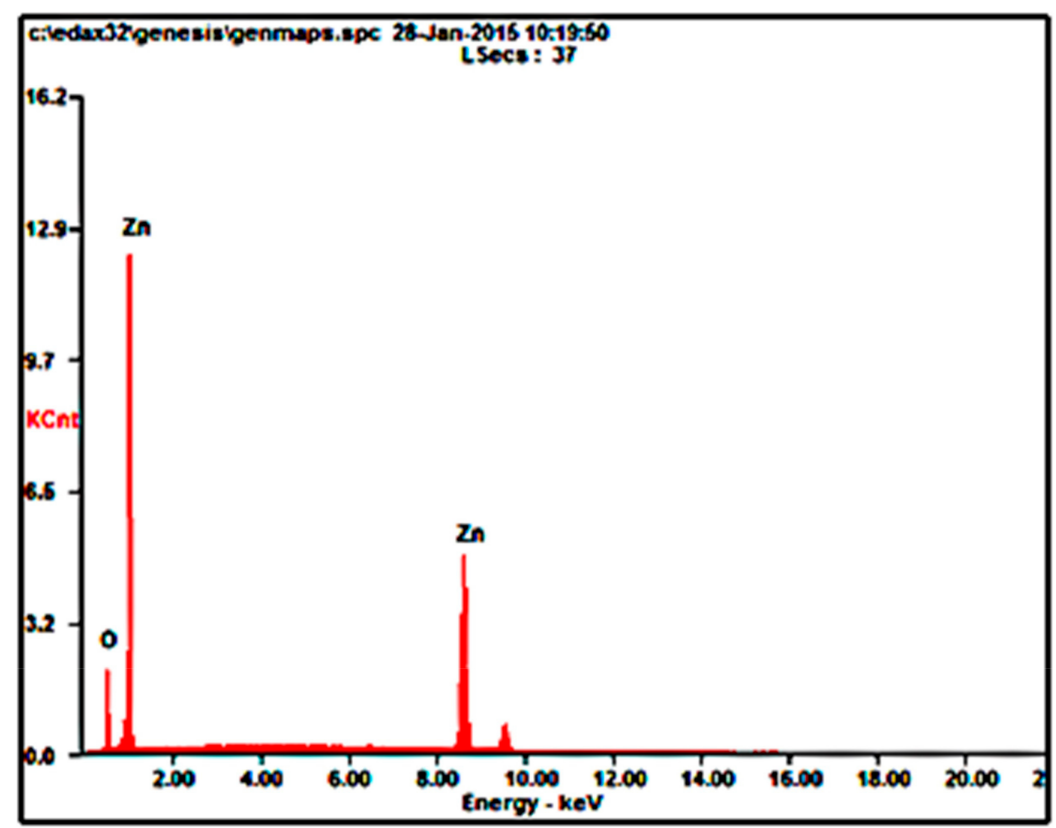

Figure 3. Energy dispersive spectroscopy (EDS) spectrum of ZNWs.

Field emission properties of the $\mathrm{ZnO}$ nanomaterials were measured using a two-parallel-plate configuration in an ultrahigh vacuum (UHV) chamber with a pressure better than $2 \times 10^{-6} \mathrm{~Pa}$ at room temperature. The sample with different morphologies was loaded on a stainless-steel holder using conducting glue to act as cathode. Another parallel nickel disk with diameter of $40 \mathrm{~mm}$ served as the anode at a fixed cathode-anode spacing of $0.6 \mathrm{~mm}$ during all the measurements. Both of the steel holder and nickel anode plates had been undergone heat treatment $\left(\sim 400^{\circ} \mathrm{C}\right)$ before mounting to remove contaminants and degassing. Before field emission measurement, vacuum bakeout $\left(\sim 200^{\circ} \mathrm{C}\right)$ was performed for degassing from the inside surface of the chamber and lead wires, then electron stimulated desorption (ESD) $[19,20]$ was used to outgassing from anode again. To examine the stability of the $\mathrm{ZnO}$ nanomaterials, field emission characteristics were measured two years later. A dc voltage was applied between the sample and anode to supply a strong electric field to extract electrons out of the $\mathrm{ZnO}$ nanomaterials under tunneling effect. The field emission and emission-stimulated desorption results from the samples are shown in Figure 4.

The relationship between the emission current $I$ and anode voltage $V$ is shown in Figure 4a. It is visible that the emission current increases exponentially with anode voltage increasing. The turn-on voltage is lower than $300 \mathrm{~V}$, which is corresponding to the turn-on field of $0.5 \mathrm{~V} / \mu \mathrm{m}$. The low turn-on field should be attributed to the high aspect ratio and small tip radius at the apex. To further analyze 
the emission properties, the classic Fowler-Nordheim (FN) law [21,22] was induced and used to describe the relationship between $\ln \left(I / V^{2}\right)$ and $1 / V$, which is shown in Figure $4 \mathrm{~b}$. The approximate linear FN plot demonstrates that the current consists of field emission electrons. It is worth noting that the field emission measurement was performed after a proper aging process (maintaining emission current at $10 \mu \mathrm{A}$ for several tens of minutes). The emission current is not high. This is because the applied electric field was not high enough. On the other hand, the effective emission area was small due to the different morphology and field screening effects. The variation of gas pressure during the field emission process was investigated and shown in Figure 4c,d. Figure 4c shows that the gas pressure increases with emission current increasing. When the anode voltage decreases, the emission current decreases and the amount of residual gas decreases (see Figure $4 \mathrm{~d}$ ). The variation of gas pressure during electron emission process should be attributed to the gas release. In general, the release of the residual gas derives from three aspects. The first is from anode. The second is from internal surface of the vacuum chamber or lead wire. The third is from the sample of $\mathrm{ZnO}$ nanomaterials. As the vacuum chamber with two parallel plates had undergone heat treatment and ESD before field emission measurement for removal of contaminants and degassing, it can be inferred that the residual gas released from the sample. The gas desorption from the field emitters may be caused by several effects including thermal effects and surface state variations, all of which is stimulated by the emission process. Therefore, emission-stimulated desorption was defined and investigated in the way of monitoring the variation of pressure. The gas released from the $\mathrm{ZnO}$ nanomertials is beneficial for electron emission since the work function of $\mathrm{ZnO}$ will decrease slightly with gas desorption. The effects of adsorption-desorption on the work function of emitters have been explored by Spindt et al. [23]. The effects of work function on the field emission properties can be found based on the FN equation. Although the ion pump of the vacuum system was working all the time, there was also some residual gas which was not taken away in time. Therefore, the gas released from the $\mathrm{ZnO}$ surface may go through several cycles of adsorption and desorption before being pumped out totally.

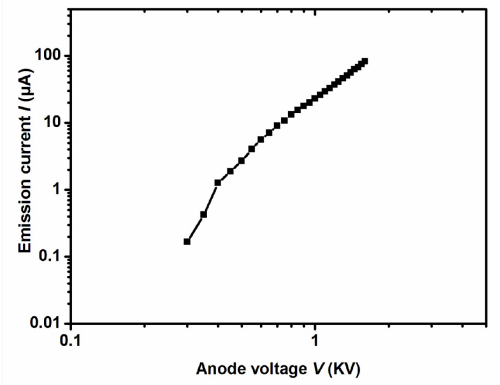

(a)

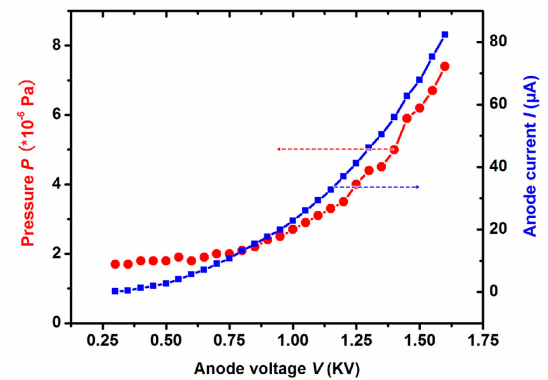

(c)

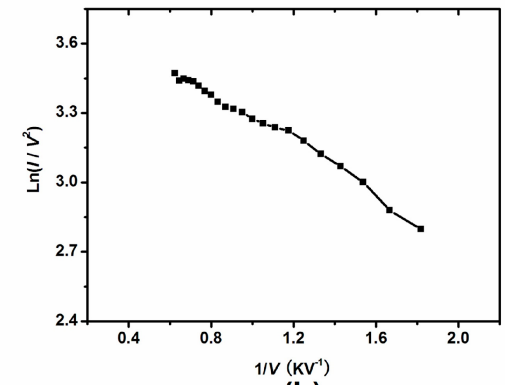

(b)

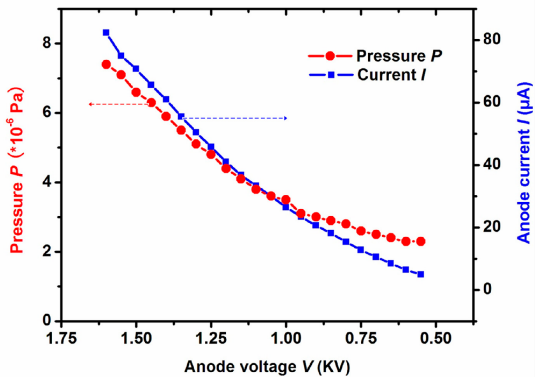

(d)

Figure 4. Field emission and emission stimulated desorption characteristics of $\mathrm{ZnO}$ nanomaterials. (a) Current-voltage plots of the field emission from $\mathrm{ZnO}$ nanomaterials. (b) The corresponding Fowler-Nordheim (FN) plots. (c) Pressure variation during field emission with anode voltage increasing. (d) Pressure variation during field emission with anode voltage decreasing. 
The stability test was performed, and the corresponding results are shown in Figure 5. Figure 5a shows current-voltage characteristics of the sample of $\mathrm{ZnO}$ nanometerials for a 10-times cyclic test. It can be found that the emission current was improved once cycle at a time. This is because the emission-stimulated desorption of the residual gas from $\mathrm{ZnO}$ surface will help to reduce the barrier which blocks the electron emission. A low turn-on voltage in the range of $0.5-0.9 \mathrm{~V} / \mu \mathrm{m}$ was obtained. The variation of the turn-on voltage should be attributed to the field emission from different structure or the tip blunting with long-time emission. Finally, an enhanced and stable emission current was obtained. The maximum emission current is not high since the applied voltage is not large enough and the effective emission area is small. The maximum applied voltage is lower than $1.6 \mathrm{KV}$ (corresponding to the electric field $\sim 2.67 \mathrm{~V} / \mu \mathrm{m}$ ), which is even smaller than the turn-on field of $\mathrm{ZnO}$ nanomaterials in many other works [24-26]. As is shown in Figure 2, the $\mathrm{ZnO}$ sample is cover with several kinds of $\mathrm{ZnO}$ nanostructures. Zhao et al. [27] have reported that the morphology of $\mathrm{ZnO}$ nanostructure has considerable effects on the turn-on field and emission current. It has been demonstrated that the nanoneedle arrays with the highest aspect ratio emitted electrons firstly at a relative lower voltage. The sharper tip of $\mathrm{ZnO}$ nanoneedles will be blunted with the emission current increase due to the thermal cumulative effects. Then other nanostructures with a lower aspect ratio or larger tip radius_-including nanowires, nanorods, and nanocombs-will gradually participate in the emission. Figure $5 \mathrm{~b}$ shows the emission-current stability at anode voltage of $1.3 \mathrm{KV}$ for more than two hours. The emission current increases at first $40 \mathrm{~min}$, which should be attributed to the slight decrease of work functions caused by gas released under the emission-stimulated-desorption effect. A sudden current drop can be found after about $50 \mathrm{~min}$. It is speculated that the sudden drop is caused by obtuseness of some sharp emitting tips under long-time thermal cumulative effect. When the work function of $\mathrm{ZnO}$ nanomaterials was stable after the emission-stimulated desorption and some sharper tips were blunted after long-time emission, the emission current became stable, as shown in Figure $5 \mathrm{~b}$.

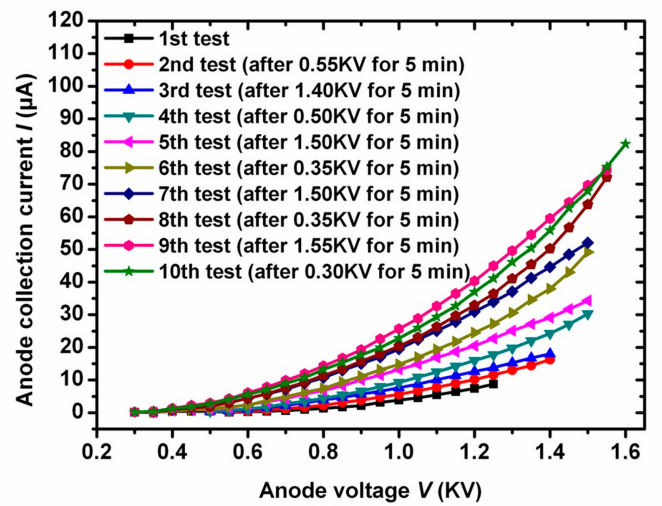

(a)

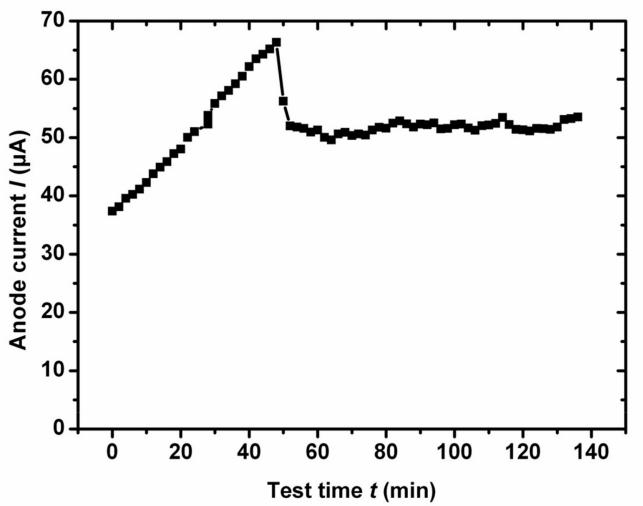

(b)

Figure 5. Field emission stability of ZnO nanomaterials. (a) Current-voltage plots of the field emission from $\mathrm{ZnO}$ nanomaterials for the 10-times cyclic test. (b) Stability test results of field emission current.

\section{Discussion}

It is known that reactive oxygen species originating from oxygen gas and water vapor are adsorbed easily on the surface of $\mathrm{ZnO}$ nanomaterials. The adsorbed species will become negatively charged by capturing a free electron from the $\mathrm{ZnO}$ nanomaterials. A highly resistive depletion layer will be formed on the surface of $\mathrm{ZnO}$ nanomaterials. The changes of the surface state will increase the effective work function of $\mathrm{ZnO}$ nanomaterial. Despite all this, the $\mathrm{ZnO}$ nanomaterial exhibits good stability during the field emission process, which confirms that $\mathrm{ZnO}$ nanomaterials are suitably used in field emitter devices. Emission-stimulated desorption is accompanied with electron emission. In this work, the emission-stimulated desorption was investigated. The gas released was measured in the way of 
examining the corresponding variation of pressure. It can be found that the amount of the released gas increases with field emission current increases. The residual gas can also be adsorbed again on the surface, and then has effects on the field-emission properties. In our test, the vacuum ion pump was working all the time. Thus, the gas released from the $\mathrm{ZnO}$ nanomaterials surface will be discharged finally after several desorption and adsorption cycles. Field emission was enhanced with the emission stimulated desorption. Finally, an enhanced and stable emission current was obtained. The emission stability of $\mathrm{ZnO}$ nanomaterials under different pressures demonstrates the feasibility of using field emission cathodes in a harsh environment.

\section{Conclusions}

1D ZnO nanomaterials have some unique properties—such as high melting point, high thermal and chemical stability, and ambient insensitivity—which makes them have promising potential applications as field emitters in harsh environment. This work investigated the field emission and emission-stimulated desorption characteristics of $\mathrm{ZnO}$ nanomaterials. Firstly, a water-assisted physical vapor deposition method was proposed and used to prepare various $\mathrm{ZnO}$ nanostructures simultaneously on a silicon substrate with one experimental run. Then, SEM and EDS were used to analyze the morphology and composition of $\mathrm{ZnO}$ nanomaterials. Finally, field-emission properties were measured. Emission-stimulated desorption was investigated. Field-emission properties can be improved by emission-stimulated desorption. A low turn-on voltage in the range of $0.5-0.9 \mathrm{~V} / \mu \mathrm{m}$ was achieved. An enhanced and stable emission current was obtained. The stability in harsh environments with fluctuating pressure demonstrates that $\mathrm{ZnO}$ nanomaterials have potential applications as field emission cathodes in harsh environments with fluctuating pressure. The $\mathrm{ZnO}$ nanomaterials are suited for various applications because of their unique properties. When $\mathrm{ZnO}$ nanomaterials are considered for use as field emission cathodes, there are many things to research. For example, the geometrical shape and uniformity of the emitters should be optimized to enhance the emission current. This provides a direction for our future research work.

Acknowledgments: This work is supported by the National Science Foundation of China (grant 61571103; grant 11375155). The authors wish to thank Yi Luo for the guidance on this paper.

Author Contributions: Nannan Li performed the fabrication and field emission test experiments, analyzed the data, and wrote an article; Xiaozhao Li help to analyze the data and participated in the discussion of the results; Baoqing Zeng proposed the idea of using a water assisted zinc source method in the fabrication of $\mathrm{ZnO}$ nanomaterials.

Conflicts of Interest: The authors declare no conflict of interest.

\section{References}

1. Di, A.B.; Passacantando, M.; Niu, G.; Schlykow, V.; Lupina, G.; Giubileo, F.; Schroeder, T. Observation of field emission from GeSn nanoparticles epitaxially grown on silicon nanopillar arrays. Nanotechnology 2016, 27, 485707. [CrossRef]

2. Chang, Y.M.; Lin, M.L.; Lai, T.Y.; Lee, H.Y.; Lin, C.M.; Wu, Y.C.; Juang, J.Y. Field emission properties of gold nanoparticle-decorated ZnO nanopillars. ACS Appl. Mater. Interface 2012, 4, 6676-6682. [CrossRef] [PubMed]

3. Lim, Y.D.; Hu, L.; Xia, X.; Ali, Z.; Wang, S.; Tay, B.K.; Aditya, S.; Miao, J. Field emission properties of $\mathrm{SiO} 2-$ wrapped CNT field emitter. Nanotechnology 2018, 29, 015202. [CrossRef] [PubMed]

4. Fujishige, M.; Wongwiriyapan, W.; Muramatsu, H.; Takeuchi, K.; Arai, S. Field emission properties of a DWCNT bundle and a single MWCNT. J. Phys. Chem. Solids 2017, 113. [CrossRef]

5. Giubileo, F.; Di, A.B.; Iemmo, L.; Luongo, G.; Passacantando, M.; Koivusalo, E.; Hakkarainen, T.V.; Guina, M. Field Emission from Self-Catalyzed GaAs Nanowires. Nanomaterials 2017, 7. [CrossRef] [PubMed]

6. Lemmo, L.; Di, A.B.; Giubileo, F.; Luoongo, G.; Passacantando, M.; Niu, G.; Hatami, F.; Skibitzki, O.; Schroeder, T. Graphene enhanced field emission from InP nanocrystals. Nanotechnology 2017, 28, 495705. [CrossRef] 
7. Ke, Y.L.; Liao, M.X.; Li, Y.F.; Deng, S.Z.; Xu, N.S.; Chen, J. In-situ measurement of temperature dependence of emission current and pressure of a fully-sealed $\mathrm{ZnO}$ nanowire field emission device. In Proceedings of the Vacuum Nanoelectronics Conference (IVNC), Engelberg, Switzerland, 6-10 July 2014; IEEE: Piscataway, NJ, USA. [CrossRef]

8. Wang, X.D.; Zhou, J.; Lao, C.S.; Song, J.H.; Xu, N.S.; Wang, Z.L. In Situ Field Emission of Density-Controlled ZnO Nanowire Arrays. Adv. Mater. 2010, 19, 1627-1631. [CrossRef]

9. Shi, Z.; Ding, T.; Wu, J.; Xu, C. Growth and Field Emission Properties of Flower-Like ZnO Nanoneedles by the Hydrothermal Method on Si Substrates. Nanosci. Nanotechnol. Lett. 2013, 5, 267-270. [CrossRef]

10. Kim, S.H.; Umar, A. Fabrication and Characterization of ZnO Nanoneedles Based Field Emission Device. Nanosci. Nanotechnol. Lett. 2016, 8, 885-889. [CrossRef]

11. Cao, P.J.; Han, S.; Wang, X.; Liu, W.J.; Jia, F.; Zeng, Y.X.; Zhu, D.L.; Lu, Y.M. Fabrication and Field Emission Properties of ZnO Nanorod Arrays with Different Orientation Degrees. Nanosci. Nanotechnol. Lett. 2017, 9 , 526-532. [CrossRef]

12. Wang, B.; Wu, H.Y.; Zheng, Z.Q.; Yang, Y.H. Field emission and photoluminescence of ZnO nanocombs. Appl. Phys. A 2013, 113, 549-556. [CrossRef]

13. Zhang, H.; Li, M.K.; Zhang, J.; Yu, L.Y.; Liu, L.L.; Yang, Z. Field Emission Properties of Aligned ZnO Nanowire Arrays Prepared by Simple Solution-Phase Method. Acta Phys.-Chim. Sin. 2010, 26, 2563-2568. [CrossRef]

14. Yu, D.; Tarek, T.; McLeskey, J.T., Jr.; Craciun, V.; Taylor, C.R. ZnO Nanowires Synthesized by Vapor Phase Transport Deposition on Transparent Oxide Substrates. Nanoscale Res. Lett. 2010, 5, 1333-1339. [CrossRef] [PubMed]

15. Lyu, S.C.; Zhang, Y.; Lee, C.J.; And, H.R.; Lee, H.J. Low-Temperature Growth of ZnO Nanowire Array by a Simple Physical Vapor-Deposition Method. Chem. Mater. 2003, 15, 3294-3299. [CrossRef]

16. Reynolds, D.C.; Look, D.C.; Jogai, B.; Litton, C.W.; Collins, T.C.; Harsch, W.; Cantwell, G. Neutral-Donor-bound-exciton complexes in ZnO crystals. Phys. Rev. B 1998, 57, 12155-74065. [CrossRef]

17. Look, D.C.; Hemsky, J.W.; Sizelove, J.R. Residual native shallow donor in ZnO. Phys. Rev. Lett. 1999, 82, 2552-2555. [CrossRef]

18. Wang, Z.L.; Kong, X.Y.; Zuo, J.M. Induced growth of asymmetric nanocantilever arrays on polar surfaces. Phys. Rev. Lett. 2003, 91, 185502. [CrossRef] [PubMed]

19. Madey, T.E.; Yates, J.T. Electron-stimulated desorption as a tool for studies of chemisorption: A review. J. Vac. Sci. Technol. 1971, 8, 525-555. [CrossRef]

20. Ramsier, R.D.; Yates, J.T., Jr. Electron-stimulated desorption: Principles and applications. Surf. Sci. Rep. 1991, 12, 246-378. [CrossRef]

21. Fowler, R.H.; Nordheim, L.W. Electron emission in intense electric fields. Proc. R. Soc. Lond. Ser. A 1928, 119, 173-181. [CrossRef]

22. Murphy, F.L.; Good, R.H. Thermionic Emission, Field Emission, and the Transition Region. Phys. Rev. 1956, 102, 1464-1473. [CrossRef]

23. Busta, H.H.; Zimmerman, B.J.; Pogemiller, J.E.; Tringides, M.C.; Spindt, C.A. Temperature dependence of I-V characteristics of vacuum triodes from 24 to 300 K. J. Vac. Sci. Technol. B Microelectr. Nanometer Struct. Process. Meas. Phenom. 1993, 11, 400-402. [CrossRef]

24. Zhu, Y.W.; Zhang, H.Z.; Sun, X.C.; Feng, S.Q.; Xu, J.; Zhao, Q.; Xiang, B.; Wang, R.M.; Yu, D.P. Efficient field emission from ZnO nanoneedle arrays. Appl. Phys. Lett. 2003, 83, 144-146. [CrossRef]

25. Chu, F.H.; Huang, C.W.; Hsin, C.L.; Wang, C.W.; Yu, S.Y.; Yeh, P.H.; Wu, W.W. Well-aligned ZnO nanowires with excellent field emission and photocatalytic properties. Nanoscale 2012, 4, 1471-1475. [CrossRef] [PubMed]

26. Zhang, Z.; Song, X.; Chen, Y.; She, J.; Deng, S.; Xu, N.; Chen, J. Controllable preparation of 1-D and dendritic $\mathrm{ZnO}$ nanowires and their large area field-emission properties. J. Alloys Compd. 2017, 690, 304-314. [CrossRef]

27. Zhao, Q.; Zhang, H.Z.; Zhu, Y.W.; Feng, S.Q.; Sun, X.C.; Xu, J.; Yu, D.P. Morphological effects on the field emission of ZnO nanorod arrays. Appl. Phys. Lett. 2005, 86, 203115. [CrossRef]

(C) 2018 by the authors. Licensee MDPI, Basel, Switzerland. This article is an open access article distributed under the terms and conditions of the Creative Commons Attribution (CC BY) license (http:/ / creativecommons.org/licenses/by/4.0/). 